\title{
Autoimmune Thyroid Diseases in Children
}

\author{
Marco Cappa, Carla Bizzarri, and Francesca Crea \\ Unit of Endocrinology and Diabetes, Bambino Gesù Children's Hospital, University of Rome "Tor Vergata”, \\ Piazza S. Onofrio 4, 00165 Rome, Italy
}

Correspondence should be addressed to Marco Cappa, cappa@opbg.net

Received 28 August 2010; Revised 10 October 2010; Accepted 19 October 2010

Academic Editor: Gary L. Francis

Copyright ( $) 2011$ Marco Cappa et al. This is an open access article distributed under the Creative Commons Attribution License, which permits unrestricted use, distribution, and reproduction in any medium, provided the original work is properly cited.

The two major autoimmune thyroid diseases (ATDs) include Graves' disease (GD) and autoimmune thyroiditis (AT); both of which are characterized by infiltration of the thyroid by $\mathrm{T}$ and $\mathrm{B}$ cells reactive to thyroid antigens, by the production of thyroid autoantibodies and by abnormal thyroid function (hyperthyroidism in GD and hypothyroidism in AT). While the exact etiology of thyroid autoimmunity is not known, it is believed to develop when a combination of genetic susceptibility and environmental encounters leads to breakdown of tolerance. It is important to recognize thyroid dysfunction at an early stage by maintaining an appropriate index of suspicion.

\section{Introduction}

Autoimmune thyroid disease (ATD) is the most common autoimmune condition, affecting approximately $2 \%$ of the female population and $0.2 \%$ of the male population [1]. Its overall prevalence peaks in adulthood; it is also the most common etiology of acquired thyroid dysfunction in paediatrics. It is more common in females and usually occurs in early to mid-puberty $[2,3]$. Optimal quantities of thyroid hormone are critical to neurodevelopment and growth. The paediatrician can often recognize thyroid dysfunction in its early stages, by maintaining an appropriate index of suspicion.

This review will analyze current opinions and options regarding the etiology, evaluation, diagnosis, treatment, and prognosis of ATDs in children.

1.1. Etiology. ATD arises due to complex interactions between environmental and genetic factors, that are yet to be completely defined. ATD is multifactorial in that a genetic predisposition combines with environmental risk factors to promote disease.

Early evidence that ATD has a hereditary component stems from studies of familial aggregation. Several studies of young people with ATDs showed a definite genetic propensity for thyroid autoimmunity to run in families [4]. Further evidence of the genetic control of ATDs comes from the observation of twins. Monozygotic twins show a higher concordance rate of disease than dizygotic twins. However, even with identical twins the concordance rate is only about $50 \%$, emphasizing that other important factors, such as the environment, play a role in disease pathogenesis [5-7]. The identified ATDs susceptibility genes can be divided into two broad groups:

(1) immune modulating genes, and

(2) thyroid specific genes.

The immune modulating genes so far identified are: HLA-DR, CTLA-4, CD40, and PTPN22. The cytotoxic T lymphocyte-associated factor 4 (CTLA-4) gene is a major negative regulator of T-cell activation [8]. CTLA-4 activation has been shown to suppress several experimental autoimmune diseases. CD40 [9] is expressed primarily on $\mathrm{B}$ cells and other antigen presenting cells (APCs) and plays a fundamental role in B-cell activation inducing, upon ligation, B-cell proliferation, immunoglobulin class switching, antibody secretion, and generation of memory cells. The lymphoid tyrosine phosphatase, encoded by the protein tyrosine phosphatase-22 (PTPN22) gene, like CTLA4 , is a powerful inhibitor of T-cell activation [10]. Recently, linkage studies mapped ATDs susceptibility loci in two thyroid specific genes, the thyroglobulin (TG) [11] and TSH receptor (TSHr) genes [12], that represent the main targets of the immune response in ATDs. 
Polymorphic variations of all the cited genes have been identified and linked to ATDs susceptibility, but the existing studies have often given inconsistent results, with some showing associations and others not. One of the many unexpected findings of these genetic studies is that most of the identified genes have a very minor effects. Indeed, with the exception of the DRb1-Arg74 HLA variant, which gave an odd ratio for Graves' disease (GD) of $>5$, all the other ATDs genes gave very low odd ratios of $<1.5$ [13]; on the other hand, family history is positive in about $50 \%$ of patients with ATDs. It is usually supposed that a strong genetic effect on disease is related to the inheritance of many genes with small effect. Two alternative mechanisms have been proposed for the finding of very low odd ratios for most ATDs genes [4]: subset effect and gene-gene interactions. According to the "gene-gene interaction" model, two genes with weak effects (i.e., associated with low odd ratios) interact, biologically resulting in a combined odd ratio that is significantly higher than the one expected with an additive effect alone. For example, two genes with odd ratios for disease of 1.2 when inherited together would give an odd ratio of $1.44(1.2 \times 1.2)$, if there was only an additive effect. If there is an interaction between these two genes, the odd ratio for disease will be significantly higher. According to the "subset effect" model (also called genetic heterogeneity), each of the genetic variants identified has a large effect resulting in a high odd ratio in a subset of the ATDs patients studied. On the contrary, when these variants are tested in the entire population of ATDs patients, their effects are diluted, resulting in much smaller odd ratios.

A recent twin study estimated that $79 \%$ of the liability to the development of GD is attributable to genetic factors [14]. Therefore, about $20 \%$ of the liability to develop GD is due to nongenetic factors. Among the nongenetic factors postulated to precipitate ATDs are iodine $[15,16]$ and medications such as amiodarone [17] and interferon $\alpha$ [18], infections, smoking, and stress. Amiodarone is a benzofuranic-derivative iodine-rich drug widely used for the treatment of tachyarrhythmias. It often causes changes in thyroid function tests (typically an increase in serum $\mathrm{T}_{4}$ and $\mathrm{rT}_{3}$ and a decrease in serum $\mathrm{T}_{3}$ concentrations), mainly related to the inhibition of $5^{\prime}$-deiodinase activity. In 14-18\% of amiodarone-treated patients, there is overt thyroid dysfunction, either amiodarone-induced thyrotoxicosis (AIT) or amiodarone-induced hypothyroidism (AIH). Both AIT and AIH may develop either in apparently normal thyroid glands or in glands with preexisting, clinically silent abnormalities. Preexisting Hashimoto's thyroiditis is a definite risk factor for the occurrence of AIH. The pathogenesis of iodine-induced $\mathrm{AIH}$ is related to a failure to escape from the acute WolffChaikoff effect due to defects in thyroid hormonogenesis and, in patients with positive thyroid autoantibody tests, to concomitant Hashimoto's thyroiditis. AIT is primarily related to excess iodine-induced thyroid hormone synthesis in an abnormal thyroid gland (type I AIT) or to amiodaronerelated destructive thyroiditis (type II AIT), but mixed forms frequently exist [17].

A few studies have shown seasonality $[19,20]$ and geographic variation [21] in the incidence of GD, adding evidence that infectious agents may trigger ATDs. Moreover, several infectious agents have been implicated including Yersinia enterocolitica [22, 23], Coxsackie B virus [24], retroviruses [25, 26], and Helicobacter pylori [27].

By now, the strongest association of ATDs with an infectious agent is with hepatitis $\mathrm{C}$ virus (HCV) [28]. In most studies examining the frequency of thyroid disorders in hepatitis C patients, approximately $10 \%$ of the patients had positive autoantibodies prior to initiation of interferon therapy $[29,30]$. Pooling of data from all studies on HCV infection and thyroid autoimmunity demonstrated a significant increase in the risk of ATDs in HCV patients [31].

Two main theories have been proposed for the induction of autoimmunity by infectious agents: (1) the "molecular mimicry" theory suggests that sequence similarities between viral or bacterial proteins and self proteins can induce a cross-over immune response to self antigens [32]; (2) the "bystander activation" theory proposes that viral infection of a certain tissue can induce local inflammation and cytokine release, resulting in activation of autoreactive $\mathrm{T}$ cells, that were suppressed by peripheral regulatory mechanisms [33].

\section{Autoimmune Thyroiditis (AT)}

The childhood prevalence of chronic autoimmune thyroiditis (AT) peaks in early to mid-puberty, and a female preponderance of $2: 1$ has been reported [34]. Presentation is rare under the age of 3 years, but cases have been described even in infancy [35].

2.1. Terminology and Definitions. In 1912, Hashimoto described four women with goiter and the apparent transformation of thyroid into lymphoid tissue (struma lymphomatosa). These patients comprise the first report of Hashimoto's disease, which we now recognize as a form of AT. Improvements in the measurement of circulating autoantibodies and ultrasonography have obviated the need for biopsy in the diagnosis of AT. The term thyroiditis is defined as evidence of "intrathyroidal lymphocytic infiltration" with or without follicular damage. Two types of AT (also defined as chronic lymphocytic thyroiditis) are causes of persistent hypothyroidism: Hashimoto's disease (goitrous form) and atrophic thyroiditis (nongoitrous form). Both are characterized by circulating thyroid autoantibodies and varying degrees of thyroid dysfunction, differing only by the presence or absence of goiter. Transient thyroiditis seems to be a variant presentation of AT. It is characterized by an autoimmune-mediated lymphocytic inflammation of the thyroid gland resulting in a destructive thyroiditis with release of thyroid hormone and transient hyperthyroidism, frequently followed by a hypothyroid phase and full recovery. The condition is particularly common in the postpartum period, but it has been observed also in children. The term chronic AT does not include subacute (de Quervain's) thyroiditis.

2.2. Pathophysiology. The activation of CD4 (helper) Tlymphocytes specific for thyroid antigens is believed to be the first step in pathogenesis. Once activated, self-reactive CD4 
T cells recruit cytotoxic CD8 T cells as well as autoreactive B cells into the thyroid. The three main targets of thyroid antibodies are thyroglobulin (TG), thyroid peroxidase (TPO), and the TSH receptor (TSHr). Anti-TPO antibodies have been shown to inhibit the activity of the enzyme in vitro, but direct cytotoxicity by CD8 T cells is believed to be the main mechanism of hypothyroidism in vivo. Anti-TSHr antibodies of the blocking type may contribute to hypothyroidism in a minority of adult patients with the atrophic form of AT, but this has not been proven in children. Histologically, goitrous AT is characterized by diffuse lymphocytic infiltration with occasional germinal centers. Thyroid follicles may be reduced in size and contain sparse colloid. Individual thyroid cells are often enlarged with oxyphilic cytoplasm (usually defined Hurthle cells). In contrast, the gland of atrophic AT is small, with lymphocytic infiltration and fibrous replacement of the parenchyma [36].

2.3. Clinical Aspects. AT is usually suspected in the presence of goiter, even in the absence of signs and symptoms of thyroid dysfunction. It may also be diagnosed incidentally during medical checkups, screening evaluation of children with growth defects, or followup of children with associated diseases, mainly Down syndrome, Turner syndrome, type 1 diabetes, and celiac disease [37-39]. Additionally, a recent study [40] analyzed morpho-volumetric and functional thyroid abnormalities in young patients with Williams syndrome: $31.5 \%$ had subclinical hypothyroidism with TSH above the upper normal limit and normal $\mathrm{FT}_{3}$ and $\mathrm{FT}_{4}$ concentrations, and $67.5 \%$ had morphological or volumetric abnormalities of the thyroid gland at ultrasonography. AntiTPO antibodies and anti-TG antibodies were absent in all patients, suggesting embrional defect of thyroid morphogenesis and/or a delayed maturation of the hypothalamicpituitary-thyroid axis, instead of an ATD, more common in the other syndromes.

In all patients with associated diseases, AT is usually detected in its initial phase when thyroid function is preserved, with normal or only slightly elevated TSH levels. At this stage, signs and symptoms of thyroid disease are usually absent, but because worsening of thyroid function is a possibility, early recognition of thyroid dysfunction is necessary to prevent the negative effects of hypothyroidism on growth and metabolic function. The enlarged thyroid gland usually is diffuse and nontender; sometimes the gland may be firm [36]. As the disease progresses, subclinical and then clinical hypothyroidism appears. Symptoms of hypothyroidism may be subtle, even with marked biochemical derangement (Table 1). The initial history should investigate energy level, sleep pattern, menses, cold intolerance, and school performance. In addition to palpation of the thyroid, assessment of the extra ocular movements, fluid status, and deep tendon reflexes are important components of the physical examination. AT may be the initial presentation of an autoimmune polyglandular syndrome, and the possibility of coexisting autoimmune diseases such as type 1 diabetes, celiac disease, Addison's disease, and pernicious anemia must be addressed by the past medical history. Screening for other autoimmune diseases should be undertaken if
TABLE 1: Symptoms and signs of overt hypothyroidism.

\author{
Goiter \\ Poor linear growth with increased weight for height \\ Bone maturation delay \\ Pubertal disorders (pubertal delay or pseudoprecocious \\ puberty) \\ Irregular menstrual periods \\ Lethargy and/or impaired school performance \\ Fatigue \\ Bradycardia and decreased cardiac output \\ Constipation \\ Cold intolerance \\ Hypothermia \\ Fluid retention and weight gain (due to impaired renal \\ free water clearance) \\ Puffiness of the face \\ Dry skin \\ Increased body hair \\ Delayed relaxation phase of the deep tendon reflexes
}

clinically indicated. Growth and pubertal development may be deranged. Similar to other endocrine causes of growth failure, linear growth is compromised to a greater degree than weight gain, and the bone age is delayed [41, 42]. Hypothyroidism typically causes pubertal delay but may also induce pseudoprecocious puberty, manifested as testicular enlargement in boys, breast development, and/or vaginal bleeding in girls [43-45]. This syndrome clinically differs from true precocity by the absence of accelerated bone maturation and linear growth.

2.4. Diagnosis. The serum TSH concentration is elevated in primary hypothyroidism and its determination is an appropriate screening test for thyroid dysfunction. If the differential diagnosis includes central hypothyroidism or if the overall suspicion for overt hypothyroidism is high, $\mathrm{FT}_{4}$ should be included. In mild hypothyroidism, serum $\mathrm{FT}_{3}$ can remain in the normal range due to the increased conversion of $\mathrm{FT}_{4}$ to $\mathrm{FT}_{3}$ by type 2 deiodinase and the preferential secretion of $\mathrm{FT}_{3}$ by residual thyroid tissue under the influence of high TSH levels [46]. For these reasons, measurement of the serum $\mathrm{T}_{3}$ and $\mathrm{FT}_{3}$ concentration is not a useful test in the diagnosis or monitoring of patients with primary hypothyroidism. The presence of goiter or high TSH levels should prompt the measurement of antiTPO antibodies. Anti-TPO antibodies are the most sensitive screen for AT. Little further benefit is gained by the additional measurement of anti-TG antibodies, although they may be added if anti-TPO titers are negative [47]. Ultrasonography of the gland shows characteristic structural abnormalities such as generalized hypoechoicity and disomogeneity, due to inflammation and diffuse lymphocytic infiltration with occasional germinal centers (pseudonodules). A diffuse 
fibrosis of the gland can become evident at a later stage of the disease [48].

We recommend thyroid ultrasound to confirm AT diagnosis and to investigate the appearance of thyroid nodules during followup, although it is not considered as a standard of care.

The typical patient with hypothyroidism secondary to AT will have an elevated TSH ("typically" over $10 \mathrm{IU} / \mathrm{mL}$ ), a low $\mathrm{FT}_{4}$, and positive anti-TPO antibodies. In early stages of the disease, TSH may be normal and anti-TPO antibodies may be positive with or without goiter. Later, TSH elevation becomes modest $(5-10 \mathrm{IU} / \mathrm{mL})$ with a normal $\mathrm{FT}_{4}$ (biochemical or subclinical hypothyroidism). Up to $90 \%$ of patients with hypothyroidism secondary to AT are anti-TPO antibody positive. It should be noted that $10-15 \%$ of the general population are positive for anti-TPO antibodies and that low titers (less than 1/100 by agglutination methods or less than $100 \mathrm{IU} / \mathrm{L}$ by immunoassays) are less specific for ATDs [1].

If anti-TPO antibodies are absent, less common etiologies of primary hypothyroidism should be considered: transient hypothyroidism due to postsubacute thyroiditis, hypothyroidism related to external irradiation [49], and consumptive hypothyroidism due to the inactivation of thyroid hormone by the paraneoplastic expression of type 3 iodothyronine deiodinase, mostly in vascular tumors [50]. Subclinical hypothyroidism is defined as TSH elevation with normal concentrations of circulating thyroid hormones $\left(\mathrm{FT}_{4}\right.$ and $\mathrm{FT}_{3}$ ). The log-linear relationship between serum TSH and $\mathrm{FT}_{4}$ explains how small reductions in serum $\mathrm{FT}_{4}$ lead to large deviations in TSH. The majority of these patients are asymptomatic, but studies in the adult population suggest that individuals with the combined risk factors of TSH level above the normal limit and positive thyroid antibodies (anti-TG or anti-TPO) are at high risk for progression to overt hypothyroidism. For this reason, we recommend thyroid hormone replacement in all patients with TSH values $>10 \mathrm{IU} / \mathrm{mL}$ or with TSH values $>5 \mathrm{IU} / \mathrm{mL}$ in combination with goiter or thyroid autoantibodies [51].

2.5. Therapy and Management. Levothyroxine $\left(\mathrm{L}-\mathrm{T}_{4}\right)$ is the replacement therapy of choice. There are virtually no adverse reactions; its good intestinal absorption and its long halflife of 5-7 days allow oral administration once a day. Although very rare, the development of pseudotumor cerebri associated with the initiation of $\mathrm{L}^{-} \mathrm{T}_{4}$ has been described in a small number of school-age children [52]. Some authors advocate a graded approach to the initiation of $\mathrm{L}^{-\mathrm{T}_{4}}$ [53]. Alternatively, a starting dose can be estimated based upon the patient's age and ideal body weight (Table 2) [34]. The medication's long half-life insures a gradual equilibration over the course of 5-6 weeks, and dosing should be individualized on the basis of biochemical monitoring [34]. TSH normalization is the goal of replacement. In our practice, we aim to reach values in the lower part of the normal range $(0.5-2 \mathrm{micro} \mathrm{IU} / \mathrm{mL})$. This will usually be associated with an $\mathrm{FT}_{4}$ in the upper half of the normal range. Thyroid function tests should be obtained about 6-8 weeks after the initiation or subsequent adjustment of the ${\mathrm{L}-\mathrm{T}_{4}}_{4}$ dosage. Very high
TABLE 2: Recommended levothyroxine $\left(\mathrm{L}^{-\mathrm{T}_{4}}\right)$ treatment doses.

\begin{tabular}{lc}
\hline Age & Dose $(\mathrm{mcg} / \mathrm{kg} /$ day $)$ \\
\hline $0-3$ months & $10-12$ \\
$3-6$ months & $8-10$ \\
$6-12$ months & $6-8$ \\
$1-3$ years & $4-6$ \\
$3-10$ years & $3-4$ \\
$10-15$ years & $2-4$ \\
$>15$ years & $2-3$ \\
Adult & $1.6-1.8$ \\
\hline
\end{tabular}

TSH levels at diagnosis can be associated with thyrotroph hypertrophy and gradual suppression over the first year of treatment $[54,55]$. Growth and sexual development should be followed systematically as in any paediatric patient. Once biochemical euthyroidism has been achieved, TSH can be monitored every 4-6 months in the growing child and yearly up to the attainment of final height. If poor compliance is suspected as the cause of treatment failure, $\mathrm{FT}_{4}$ should be measured. A serum TSH greater than twice normal, with a concomitant normal $\mathrm{FT}_{4}$ level, suggests intermittent omission of the medication. A variety of conditions or drugs may alter $\mathrm{L}-\mathrm{T}_{4}$ requirements (Table 3 ). $\mathrm{L}_{-} \mathrm{T}_{4}$ should be administered at least $20 \mathrm{~min}$ before eating or ingestion of any medication known to impair its absorption, such as calcium and iron supplements, sucralfate, potassiumbinding resins, antacids containing aluminium, and bileacids binding resins. All other medications should be checked for interactions, particularly with antidepressants and seizure medications (Table 3). Parents of children with AT should be advised that the hypothyroidism is likely to be permanent and monitoring of thyroid function for all patients should be lifelong. The prognosis for recovering lost linear growth depends on the duration of the hypothyroidism as well as the age at which treatment is started. If hypothyroidism is longstanding, thyroid replacement will not recover all lost stature. Similarly, if the diagnosis is made around puberty, there may be limited time for recovering the growth spurt before attaining final height. If the onset of childhood hypothyroidism occurs after age 2 to 3 years, no permanent intellectual damage or neurologic deficit is probable. Children affected by type 1 diabetes, celiac disease, and Down, Turner, and Williams syndrome should undergo annual thyroid function tests to ensure that hypothyroidism has not become evident.

2.6. Natural History and Prognosis. The natural history of AT in children and adolescents is not fully known. Few studies have examined the spontaneous evolution of the disease $[56,57]$. A recent Italian retrospective study described the outcome of 160 children affected with AT followed for up to 32.6 years in 20 paediatric endocrine clinics [58]. In agreement with other reports $[56,57]$, TSH concentrations showed large fluctuations over time. Analyzing all the data together, a trend toward progressively deteriorating thyroid function was evident. However, at the last observation 84 
TABLE 3: Conditions that increase $\mathrm{L}_{-} \mathrm{T}_{4}$ requirements.

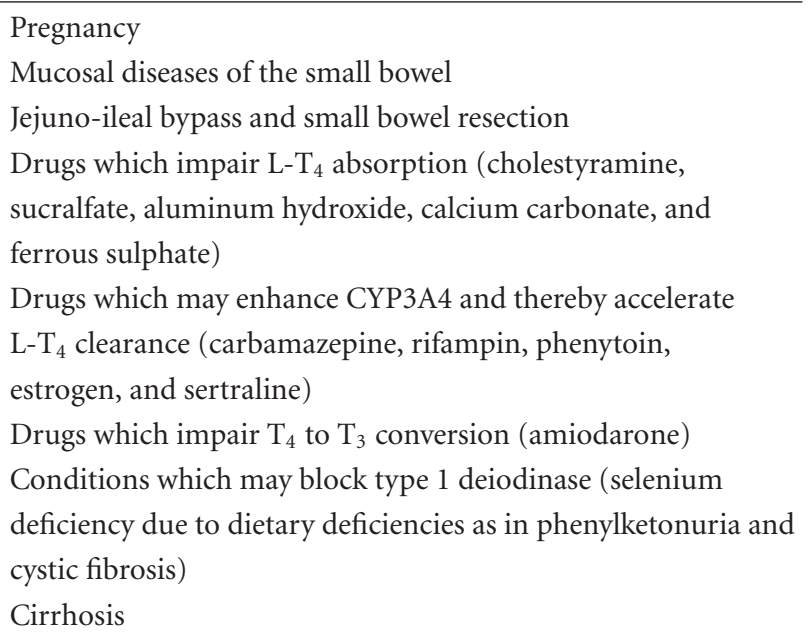

patients $(52.5 \%)$ still had a normal thyroid function or had become euthyroid. The authors analyzed reliable prognostic factors to predict disease evolution but found that clinical measures, thyroid volume, and antibody concentrations were similar in the group with normal TSH levels and the group with elevated TSH levels. The number of patients with type 1 diabetes was higher in the group with normal TSH. This can be explained by the fact that patients with autoimmune diseases are usually periodically assessed for thyroid autoimmunity, and thus many patients with mild asymptomatic forms of AT can be identified. Altogether, the presence of associated diseases did not worsen the prognosis, because at the end of the follow-up there was no difference in the frequency of abnormally elevated TSH between the groups with or without associated diseases. In agreement with previous findings in children [59-61] and in contrast with adults [62], the TSH level at baseline was not a useful marker to predict disease evolution. Both thyroid antibodies were significantly higher at the last visit in the group with deteriorating thyroid function; however, whereas anti-TG antibodies were already higher at baseline, anti-TPO antibodies increased progressively with time. This finding suggests that anti-TPO antibodies might represent a marker of deteriorating thyroid function, in agreement with a previous report showing a good correlation between anti-TPO antibodies levels and lymphocytic infiltration of the gland [63]. The evaluation of patients, according to their final outcome, revealed that subjects with deteriorating thyroid function had significantly higher anti-TG antibodies, TSH concentrations, and greater thyroid volume at presentation. Nonetheless, these findings were not helpful in individual patients. On the other hand, it should be remarked that at 5 years of followup, more than $50 \%$ of the patients remained or became euthyroid.

We usually offer a trial off $\mathrm{L}-\mathrm{T}_{4}$ therapy to adolescents, after the completion of growth and puberty. Thyroid function is retested 6-8 weeks after the stop of medication, to determine if hypothyroidism is permanent and potentially restart therapy.
2.7. Thyroid Nodules and Cancer in Patients with AT. Although unusual in children and adolescents, thyroid nodules are more often malignant in children than in adults [64, 65]. The prevalence of thyroid cancer among patients with AT is a matter of controversy. After Dailey et al. [66] reported 35 cases of AT among 288 patients with malignant thyroid disease, postulating that the disorder could be considered a precancerous lesion, other researchers seek an association between AT and thyroid cancer. Subsequent studies [67-69] reported a prevalence range of $1 \%$ to $30 \%$. Data on the occurrence of thyroid cancer in AT refer almost exclusively to adults. The overall incidence of thyroid cancer among childhood thyroid nodules was estimated to be $26.4 \%$ in a review by Niedziela [69]. A recent study [64] analyzed the relationship between AT, cancer, and thyroid nodules in a large case series of paediatric patients. Thyroid nodules were found in 115 of 365 patients with AT (31.5\%): 69 subjects $(60.0 \%)$ presented a solitary nodule, and 46 subjects $(40.0 \%)$ had multiple nodules. Thirty eight nodules (33\%) were palpable at clinical examination, and the presence of all of them was confirmed by ultrasonography. Eleven cases of papillary carcinoma were detected on histologic examination after total thyroidectomy, with 5 exhibiting lymph node metastasis. Eight patients had multifocal cancer, and 3 patients had single focus cancer. The prevalence of male sex among patients with cancer was greater than that among patients with AT (odd ratio: 2.95 ). The finding of lymphadenopathy and the progressive increase of nodule diameter during $\mathrm{L}_{-} \mathrm{T}_{4}$ therapy represented the two factors that were significantly more frequent in patients with thyroid cancer than in patients with a benign lesion. Thyroid ultrasonography provided further useful diagnostic information. Among patients with thyroid cancer, hypoechogenicity seemed to predominate over other ultrasound patterns, although it was common also in benign nodules. Multinodularity was more frequent than uninodularity in patients with cancer.

2.8. The Link between GD and AT. The observation that the autoimmune attack against the thyroid gland could result in two opposing clinical phenotypes, AT and GD, has been intriguing for decades.

In AT, the lymphocytic infiltration of the thyroid gland leads to apoptosis of thyroid cells and hypothyroidism. In contrast, in GD the lymphocytic infiltration of the thyroid leads to activation of TSHr-reactive B cells that secrete TSHr-stimulating antibodies causing hyperthyroidism. The etiology of AT and GD involves common pathways in which thyroid reactive $\mathrm{T}$ cells escape tolerance and infiltrate the thyroid, and unique pathways in which these thyroid-reactive T cells either cause thyroid cell death (in AT) or stimulation (in GD). Although GD and AT have different clinical phenotypes and the mechanisms leading to their dichotomy are unknown, they are generally believed to share a number of common etiological factors. There have been reports on monozygotic twins in whom one twin had GD and the other one had AT [70, 71]. Moreover, both conditions may aggregate in the same family [72] or may even coexist in the same thyroid gland [73], and some individuals may 
progress from one form to the other. It is more frequent that GD may spontaneously culminate in hypothyroidism due to AT [74], while the development of GD from AT as only occasionally been reported $[75,76]$. On the other hand, whole-genome scanning studies in humans have revealed differences between the specific loci linked to, or associated with, these two ATDs [77]. A recent study, performed in 109 children with GD at clinical onset [78], demonstrated that hyperthyroidism might be preceded by AT presenting either hypothyroidism or euthyroidism in at least 4 cases (3.7\%). After AT diagnosis, 3 of these patients underwent $\mathrm{L}^{-\mathrm{T}_{4}}$ therapy, which was continued for at least 1 year. In all these cases, a subsequent thyroid function evaluation, performed 1-3 months prior to the GD diagnosis, had evidenced normal $\mathrm{FT}_{4}$ and TSH serum levels. The time interval between AT diagnosis and GD presentation ranged from 1.5 to 2.8 years. All of them exhibited both thyroid enlargement and other clinical signs as well as symptoms of hyperthyroidism, while exophthalmos and even mild eye signs were not evident in any of them. Serum TSHr antibodies were higher in the patients with no AT antecedents. The clinical course of GD in patients with AT antecedents was not different from the one observed in those with no AT antecedents.

\section{Graves' Disease (GD)}

Robert Graves reported the clinical syndrome of goiter, palpitations, and exophthalmos in 1835. In adults, GD accounts for $60-80 \%$ of all patients with hyperthyroidism. Hyperthyroidism is relatively rare in children (yearly incidence of 8 per 1,000,000 children less than 15 years old and 1 per 1,000,000 children less than 4 years old), but GD is by far the most common etiology. Girls are affected four to five times more frequently than boys, although no gender difference is noted under 4 years of age [79].

3.1. Pathophysiology. GD shares many characteristics with AT, including anti-TG antibodies, anti-TPO antibodies, and antibodies against the sodium-iodine symporter. Hyperthyroidism is caused by thyroid-stimulating antibodies that bind and activate TSHr, leading to follicular cell hyperplasia and hypersecretion of thyroid hormones. Lymphocytic infiltration of the thyroid is present. Sometimes, germinal centers appear and develop as major sources of intrathyroid autoantibodies. The lymphocytic infiltration and the accumulation of glycosaminoglycans in the orbital connective tissue and skin cause the extrathyroidal manifestations of GD ophthalmopathy and dermopathy, respectively.

3.2. Clinical Aspects. The presentation of GD in childhood may be insidious and a careful history often reveals a several month history of progressive symptoms. Children may have the same signs and symptoms of hyperthyroidism as do adults, but most often they present with behavioral disturbances: decreased attention span, difficulty concentrating (which may lead to deteriorating performance in school), emotional lability, hyperactivity, difficulty sleeping, and nervousness. Typical cardiovascular findings include tachycardia, palpitations, widened pulse pressure, and an overactive
TABLE 4: Clinical signs and symptoms of hyperthyroidism in children.

Goiter
Exophthalmos
Acceleration of linear growth
Irritability
Impaired concentration and school performance
Headache
Hyperactivity
Fatigue
Palpitations
Tachycardia
Systolic Hypertension
Polyphagia
Increased frequency of bowel movements with diarrhoea
Weight loss
Heat intolerance
Increased perspiration
Tremor
Polyuria and polydipsia

precordium. Any child who has persistent tachycardia should be evaluated for hyperthyroidism. Tremors, a shortened deep tendon reflex relaxation phase, fatigue, and proximal muscle weakness are possible neuromuscular manifestations of thyrotoxicosis. Despite an increase in appetite, affected children often lose weight and sometimes have diarrhoea, but usually have frequent bowel movements associated with intestinal motility (Table 4). Increased perspiration, warmth, and heat intolerance tend to be late findings. Postpubertal girls often have menstrual irregularities. A goiter is palpable in the majority of cases, characterized by diffuse enlargement which is smooth, firm, and nontender. The pretibial myxedema that is a common feature of GD in adults is rare in children.

Extrathyroidal manifestations such as ophthalmopathy and dermopathy are rarer in children than in adults and tend to be less severe [80]. A 25-60\% frequency of ocular manifestations has been estimated in children, but usually the ocular signs are mild such as lid retraction, a slight proptosis that can be attributed to the inflammation and muscle swelling rather than to infiltrative disease of the orbital structures. As expected, these signs improve in most patients after restoration of the euthyroid state [80]. Unique to pediatric GD is the acceleration of linear growth and bone maturation associated with prolonged hyperthyroidism $[81,82]$.

3.3. Diagnosis. Even if there may be national differences in terminology, for the purposes of this study the term thyrotoxicosis refers to the manifestations of excessive quantities of circulating thyroid hormones. On the contrary, hyperthyroidism refers only to the group of diseases which are due to the overproduction of hormones by the thyroid gland. An accurate diagnosis of GD is critical as antithyroid 
drugs have no role in the treatment of thyrotoxicosis without hyperthyroidism. Thyrotoxicosis is recognized by an elevation of serum $\mathrm{FT}_{4}$ with a decreased serum TSH (typically $<0.1 \mathrm{micro} \mathrm{IU} / \mathrm{mL}$ ). A determination of the $\mathrm{FT}_{3}$ level should be added if TSH is suppressed and the serum $\mathrm{FT}_{4}$ is normal. In patients with early disease or in iodinedeficient patients, serum $\mathrm{FT}_{4}$ concentrations may be normal or reduced despite elevated levels of $\mathrm{FT}_{3}$. Once biochemical derangement has been documented, it is helpful to address the duration of thyrotoxicosis to facilitate the differentiation of GD from other causes of thyrotoxicosis. Onset may be documented by prior laboratory studies or inferred from the history. The differential diagnosis of thyrotoxicosis includes transient thyroiditis, hyperfunctioning nodules, and thyrotoxicosis factitia. In the majority of cases, the presence of a symmetrically enlarged thyroid gland, coupled with the chronicity of symptoms, will be adequate to allow a diagnosis (Table 5). If thyrotoxicosis has been present for more than 8 weeks, GD is by far the most likely etiology. The constellation of thyrotoxicosis, goiter, and orbitopathy is pathognomonic of this condition, and no additional laboratory tests or imaging studies should be necessary to confirm the diagnosis. If thyromegaly is subtle and eye changes are absent, a thyroid echography should be performed. The radioactive iodide uptake (RAIU) should be reserved for patients in whom a discrete nodule(s) is palpable or evident at ultrasonography. In patients with a toxic nodule, iodide uptake will localize to the nodule and the signal in the surrounding tissue will be low, secondary to TSH suppression. Thyrotoxicosis factitia can be recognized by a low RAIU and serum TG, in the presence of thyrotoxicosis and suppressed TSH levels. If thyrotoxicosis has been present for less than 8 weeks, transient thyrotoxicosis secondary to subacute thyroiditis or the thyrotoxic phase of AT should be considered. An elevated sedimentation rate supports subacute thyroiditis whereas increased TPO and TG without increased TSHr antibody titers supports the latter. RAIU was used in the past decades to distinguish thyrotoxicosis due to the different forms of thyroiditis (increased release of thyroid hormone-low RAIU), from the more common GD (increased production of thyroid hormone-high RAIU), but the measurement of TSHr antibodies may now offer an effective tool to make the correct diagnosis, and RAIU is no more indicated for differential diagnosis. Anti-TSHr antibodies are commonly present in GD, whereas they are absent from AT and in the other forms of thyrotoxicosis. The sensitivity of two frequently used serum anti-TSHr antibody assays is cited to be $75-96 \%$ for TBII (a competitive binding assay with TSH) and $85-100 \%$ for TSAb measurements (a bioassay of TSH receptor activation) in untreated GD patients. A false negative rate of $10-20 \%$ has been documented for serum anti-TSHr antibodies in GD, presumably due to the inadequate sensitivity of the assays, or the exclusive intrathyroidal production of autoantibodies.

In practice, the measurement of anti-TSHr antibodies is routinely used in children to avoid RAIU, as the combination of clinical signs, symptoms of thyrotoxicosis, and positive autoantibodies, in the absence of a nodule at ultrasonography, is virtually diagnostic of GD. There
TABLE 5: Differential diagnosis of thyrotoxicosis in children.

Thyrotoxicosis associated with sustained hormone overproduction (hyperthyroidism). High RAIU

Graves' disease

Toxic multinodular goiter

Toxic adenoma

Increased TSH secretion (TSH secreting adenomas)

Thyrotoxicosis without associated hyperthyroidism. Low RAIU

Thyrotoxicosis factitia

Subacute thyroiditis

Chronic autoimmune thyroiditis

Ectopic thyroid tissue (struma ovarii, functioning metastasis

of differentiated thyroid cancer)

is a subgroup of patients who have a subnormal but not severely depressed TSH (usually $0.1-0.3$ micro $\mathrm{IU} / \mathrm{mL}$ ) and normal serum concentrations of thyroid hormones. These patients are generally asymptomatic and the term "subclinical hyperthyroidism" has been applied to their condition. In elderly people, a low serum TSH concentration has been associated with an increased risk of atrial fibrillation, but no similar risks have been identified in the paediatric population [83]. Furthermore, several studies indicate that approximately half of patients with subclinical thyrotoxicosis will experience a spontaneous remission [84]. The initial detection of a suppressed TSH concentration, without elevated levels of thyroid hormone or associated symptoms, should be addressed simply by repeating thyroid function tests in 4-8 weeks. Assuming there are no specific risk factors such as a history of cardiac disease, asymptomatic children with subclinical hyperthyroidism can be followed with the expectation that TSH suppression due to transient thyroiditis will resolve spontaneously and that due to GD or autonomous secretion will declare itself clinically over time.

3.4. Antithyroid Medications. The treatment of hyperthyroidism due to GD may be divided into two categories, antithyroid medications and definitive therapy. The thionamide derivatives, methimazole (MMI) and propylthiouracil (PTU), are the most commonly used antithyroid drugs [85]. Both thionamides block thyroid hormone biosynthesis and PTU, when used at doses over 450-600 mg per day, have the additional action of inhibiting the extrathyroidal conversion of $T_{4}$ to $T_{3}$. The recommended starting dose is $0.5-1.0 \mathrm{mg} / \mathrm{kg}$ per day for MMI and $5-10 \mathrm{mg} / \mathrm{kg}$ per day for PTU. Both drugs cross the placenta, although PTU does so less and is preferred during pregnancy. Although both are present in human milk, their concentrations are low, and breastfeeding may be continued. Due to its longer halflife, MMI can be administered once or twice a day, whereas PTU should be administered three times a day. Over the 60 years that this medication has been used, reports of PTUrelated liver failure and death have been accumulated. The risk of severe PTU-induced liver failure is estimated as 1 in 2000-4000 children. The number of children developing reversible PTU-induced liver injury is estimated to be at 
least 1 in 200 children. Routine biochemical surveillance of liver function and hepatocellular integrity is not useful in identifying children who will develop liver failure. Children appear to be at higher risk for PTU-induced liver injury than adults. PTU should not be used as first line therapy for the treatment of GD in children. Current PTU use in children should be stopped in favor of alternate therapies [86, 87].

For the specific situations of severe hyperthyroidism or thyroid storm, PTU has been the preferred thionamide because of its blockade of $\mathrm{T}_{4}$ to $\mathrm{T}_{3}$ conversion, through the inhibition of type 1 iodothyronine deiodinase. In such patients, a combination of high doses of PTU (up to $1200 \mathrm{mg}$ per day divided in 4 doses) and inorganic iodine (SSKI: three drops orally twice a day, for 5-10 days) will speed the fall in circulating thyroid hormones. Some authors have advocated a "block and replace" strategy of high-dose antithyroid medication (to suppress all endogenous thyroxine secretion) combined with levothyroxine replacement. One report described a lower frequency of recurrence with this approach [88]. However, all subsequent studies have failed to duplicate this finding [89]. For the purpose of simplifying therapy and minimizing the risk of adverse effects, we usually prefer monotherapy with a single antithyroid medication. After $\mathrm{FT}_{4}$ level has fallen to the upper end of normal range, the dose of antithyroid drug should be decreased by one half or one third. Further dose adjustments are guided by serial thyroid function tests, initially relying upon the $\mathrm{FT}_{4}$. After pituitary TSH secretion recovers from suppression, the goal of maintenance therapy is TSH normalization. The "block and replace" approach is more complicated, but it can be useful in small children when the titration and tapering of the thionamide dose can be difficult: even very small doses are able to cause hypothyroidism, but the therapy cannot be stopped too early, due to the elevated risk of recurrence. The first clinical response to medications is usually evident after 2-4 weeks. Weight loss stops or weight gain occurs. Betaadrenergic antagonists may be used as an adjunct during this interval but, as the cardiovascular manifestations of hyperthyroidism are generally well tolerated in children, we reserve this therapy for symptomatically significant palpitations. Antithyroid drugs are usually well tolerated, but side effects are seen more commonly in children than in adults. Thirtysix serious complications and 2 deaths in children have been reported to the FDA [90]. Agranulocytosis (defined as a granulocyte count less than $500 /$ microL) is a serious idiosyncratic reaction that can occur with either MMI or PTU. For this reason, a baseline white count should be obtained prior to the initiation of antithyroid drugs, since mild neutropenia may be present in the GD patients prior to the initiation of treatment, and it will be repeated 7-10 days after the start of therapy. Families should be advised that fever, sore throat, or other serious infections may be manifestations of agranulocytosis and therefore should prompt the immediate cessation of antithyroid drugs, the notification of the physician, and a determination of white blood cell count.

Reports of long-term remission rates in children are variable, ranging anywhere from 30-60\% [91]. Remission rates are considerably less in prepubertal (17\%) compared to pubertal $(30 \%)$ children, but a recent retrospective study of 76 paediatric patients describes a $38 \%$ rate of longterm remission achieved with more prolonged courses of antithyroid medication (mean treatment duration of $3.3 \mathrm{yr}$ ) [92]. If the dose of antithyroid medication required to maintain euthyroidism is $5 \mathrm{mg}$ per day of MMI (or less for younger children) for 6 months to 1 year and the serum TSH concentration is normal, a trial of medication may be offered. Antithyroid drugs can be discontinued and TSH concentrations monitored at monthly intervals. If hyperthyroidism relapses, as indicated by suppressed TSH levels with elevated $\mathrm{FT}_{4}$ levels, antithyroid medications should be resumed or definitive therapy provided.

3.5. Definitive Therapy. The two options for the definitive treatment of GD are I-131 and thyroidectomy. Both usually result in life-long hypothyroidism, and there is no agreement in the literature as to their indications. Some centers consider these modalities as options for the initial treatment of paediatric hyperthyroidism [93-95]. However, considering that a remission of GD occurs in a significant percentage of children, at the onset of the disease we recommend a longterm trial with antithyroid medications (at least 2 years of continuous therapy). If the disease relapses after stopping therapy, one of the definitive therapeutical options should be considered. If patient noncompliance prevents the successful treatment, or both antithyroid medications must be discontinued secondary to serious drug reactions, the choice of a definitive therapy is appropriate. Thyroid ablation by I-131 is the first choice definitive treatment in adults, but concerns over the potential long-term complications of paediatric radiation exposure have made endocrinologists cautious in applying this approach to children [96]. The literature about GD in adults describes an increased relative risk for the development of stomach cancer ( 1.3 fold) and breast cancer (1.9 fold), but no large, long-term, follow-up studies of patients treated under 16 years of age have appeared [97]. It is estimated that more than 1000 children have received I-131 for the treatment of GD. To date, there are no reports of an increase in the incidence of thyroid carcinoma or leukaemia in this population [96, 97]. Despite the reassurances of these reports, experience with $\mathrm{X}$-rays and the Chernobyl nuclear power plant accident indicate that the carcinogenic effects of radiation to the thyroid are the highest in young children $[98,99]$. This argues for continued surveillance and, for children who fail antithyroid medication, the provision of an I-131 dose adequate to destroy all thyroid follicular cells. Some institutions administer an empiric dose of 3-15 millicuries, or a dose based upon the estimated weight of the gland (50-200 micro CI per gram of thyroid tissue) [95-97]. Efficacy is dependent upon both thyroid uptake and mass, and it is more useful to prescribe a dose which will provide approximately $200 \mathrm{micro} \mathrm{Ci} / \mathrm{g}$ estimated weight in the gland at 24 hours. Antithyroid drugs should be discontinued for 3 days prior to the administration of I-131. For children who are unable to swallow a capsule, a liquid preparation of I-131 is available

$$
\text { Dose }=\frac{200 \mathrm{micro} \mathrm{Ci} / \mathrm{g} \times \mathrm{g}(\text { thy }) \times 100}{\% \text { uptake in } 24 \mathrm{~h}} .
$$


The frequency of acute side-effects is low although vomiting has been frequently described in paediatric patients [95]. One prospective study of 443 patients ranging from 15 to 85 years of age has raised the concern that I-131 may worsen or precipitate the development of Graves' ophthalmopathy in approximately $15 \%$ of cases [100]. Severe ophthalmopathy is less common in paediatric GD, but a study addressing the risk of this presentation in children is not available. The current paediatric literature suggests that the rate of ophthalmologic exacerbation is similar amongst the various treatment modalities: $3 \%$ after I-131, $2 \%$ with thionamide derivatives, and $9 \%$ after subtotal thyroidectomy [88]. A short course of glucocorticoids is appropriate if there is rapid progression of ophthalmopathy or as prophylaxis prior to radioiodine in children with pre-existing severe ophthalmopathy. Baseline opthalmological assessment at the onset of treatment is advisable.

Thyroidectomy is rarely used electively for the definitive therapy of GD, except with massive thyromegaly (over eight times normal size or thyroid weight $>80 \mathrm{~g}$ ) or for patients in whom coexisting nodules are suspicious for carcinoma by fine needle aspiration. A meta-analysis of the paediatric literature provided the following analysis of surgical treatment: subtotal thyroidectomy relieved hyperthyroidism in $80 \%$ of patients, with $60 \%$ becoming hypothyroid. Total thyroidectomy cured hyperthyroidism in over $97 \%$ of patients with nearly universal hypothyroidism. The overall complication rate in children included a $2 \%$ incidence of permanent hypoparathyroidism, a $2 \%$ incidence of vocal cord paralysis, and a $0.08 \%$ mortality [90]. One large institution has published a series of 82 children treated surgically over $14 \mathrm{yr}$ with much better results. Bilateral subtotal resection was the most frequently performed operation $(86 \%)$ and, with a median followup of $8.3 \mathrm{yr}$. A recurrence rate of $6 \%$ is reported, while no cases of permanent recurrent laryngeal nerve palsy, permanent parathyroid disease, or death were observed [101]. The difference between the average complication rate and those in a single institution emphasizes the importance of skill and experience in the performance of this procedure [102]. Postoperative hypothyroidism is expected and it is easily treated, and all GD patients require life-long monitoring. We suggest to consider thyroidectomy only for patients who have persistently failed medical management or those whose parents or physicians do not wish to proceed with radioiodine therapy. Based on the results to date, I-131 therapy is an acceptable alternative if the surgical options are undesirable. I-131 is recommended for all patients who recur following surgery, due to the high complication rate of secondary thyroidectomy [103].

3.6. Neonatal GD. Thyroid hormones are necessary for optimal foetal and neonatal development, and the risk of malformations may be increased in the newborns to hyperthyroid mothers [104, 105]. Lack of thyroid hormones for more than a few weeks, during vulnerable periods of development, involves a risk of permanent cerebral impairment [106]. Conversely, excess amounts of thyroid hormone are associated with increased risk of foetal death and may lead to accelerated bone maturation leading to early epiphyseal fusion and growth cessation. Also long-term exposure may lead to ostepenia in adolescence and adulthood [107]. Only $0.6 \%$ of infants born to mothers with a history of GD will develop neonatal hyperthyroidism, due to the transplacental passage of thyroid-stimulating immunoglobulins. Even after definitive treatment by I-131 or thyroidectomy, women with a history of ATDs are at risk for foetal and neonatal thyroid dysfunction secondary to the persistence of maternal autoantibodies. The pregnancy of such women should be considered high risk, and the care should be coordinated between an experienced obstetrician and an endocrinologist. Foetal heart rate and growth should be monitored by regular prenatal ultrasounds. The measurement of antiTSHr antibodies during at-risk pregnancies has been recommended as a predictor for the development of foetal/neonatal GD [108]. Highly experienced ultrasonographers can often visualize the foetal thyroid. The presence of foetal goiter, tachycardia, and intrauterine growth retardation suggests foetal hyperthyroidism. In these rare patients, antithyroid drugs are administered to the mother to control foetal hyperthyroidism, this will keep the foetus euthyroid until birth. After birth, the antithyroid drugs from the mother will disappear from the foetal circulation within the first days of life. After some delay, neonatal hyperthyroidism may develop and remain until the maternal antibodies are cleared. Paediatricians should be aware that the use of maternal antithyroid medications near the time of delivery or the cotransfer of maternal anti-TSHr blocking immunoglobulins may delay the appearance of neonatal GD [107]. For highrisk infants, such as those born to mothers with high levels of anti-TSHr stimulating antibodies or those with a history of an affected sibling, clinical monitoring and thyroid function tests at birth and at 1 and 2 months of age are recommended [109]. An additional set of laboratory tests at 1 week of age is indicated for infants who have been exposed to maternal antithyroid drugs in the third trimester. Affected infants are often flushed, diaphoretic, and hyperkinetic. Goiter is common and, when severe, can endanger the infant's airway. Diarrhoea, vomiting, poor weight gain, and a transient exophthalmos may be seen. Arrhythmias and/or congestive heart failure can develop and require treatment with digoxin. Serum for confirmatory thyroid function tests $\left(\mathrm{TSH}, \mathrm{FT}_{4}\right)$ should be obtained and treatment initiated immediately. PTU (5-10 mg/kg per day) or MMI (0.5-1.0 $\mathrm{mg} / \mathrm{kg}$ per day) may be administered, orally or by gastric tube, in divided doses every 8 hours. MMI is preferred following reports of serious PTU toxicity. Inorganic iodine will speed the fall in circulating thyroid hormone, using saturated solution of potassium iodide (SSKI) (48 mg iodide/drop) at the dose of one drop per day. Iopanoic acid or sodium ipoiodate have also been used for their iodine content and their capacity to inhibit the activation of $\mathrm{T}_{4}$ to $\mathrm{T}_{3}$. As in older patients, adjunctive therapy with beta-blockers (propranolol: $2 \mathrm{mg} / \mathrm{kg}$ per day-in 4 doses) and glucocorticoids (prednisone: $2 \mathrm{mg} / \mathrm{kg}$ per day-in 2 doses) may be helpful in severe cases. Cardiac failure may occur in some cases and require treatment with digoxin. During the period of foetal and neonatal hyperthyroidism, the pituitary TSH secretion has been suppressed and the phase of neonatal hyperthyroidism 
may be followed by a phase of secondary hypothyroidism, until pituitary TSH secretion is restored.

The cumulative morbidity of neonatal Graves was estimated to be as high as $25 \%$ in the past, although it appears to be considerably lower today $[108,109]$. Potential long-term morbidity includes growth retardation, craniosynostosis, impaired intellectual function, and central hypothyroidism. The half-life of maternal immunoglobulin is approximately 14 days, so most cases of neonatal Graves will resolve after 3-12 weeks (depending upon the initial levels of antiTSHr antibodies). The history of maternal illness is critical. Adolescent women who have GD should know that, even if they are "cured," when they become pregnant, their babies eventually will be at risk.

The differential diagnosis of neonatal thyrotoxicosis includes the McCune-Albright syndrome, activating mutations of the TSH receptor and thyroid hormone resistance syndrome $[109,110]$. These non-autoimmune etiologies are rare but should be considered if thyrotoxicosis persists beyond 3 months of age.

\section{References}

[1] P. Saravanan and C. M. Dayan, "Thyroid autoantibodies," Endocrinology and Metabolism Clinics of North America, vol. 30, no. 2, pp. 315-337, 2001.

[2] I. Hunter, S. A. Greene, T. M. MacDonald, and A. D. Morris, "Prevalence and aetiology of hypothyroidism in the young," Archives of Disease in Childhood, vol. 83, no. 3, pp. 207-210, 2000.

[3] M. Segni, E. Leonardi, B. Mazzoncini, I. Pucarelli, and A. M. Pasquino, "Special features of Graves' disease in early childhood," Thyroid, vol. 9, no. 9, pp. 871-877, 1999.

[4] Y. Tomer, "Genetic susceptibility to autoimmune thyroid disease: past, present, and future," Thyroid, vol. 20, pp. 715$725,2010$.

[5] A. Iicki, C. Marcus, and F. A. Karlsson, "Hyperthyroidism and hypothyroidism in monozygotic twins: detection of stimulating and blocking THS receptor antibodies using the FRTL5-cell line," Journal of Endocrinological Investigation, vol. 13, no. 4, pp. 327-331, 1990.

[6] J.-I. Tani, K. Yoshida, H. Fukazawa et al., "Hyperthyroid Graves' disease and primary hypothyroidism caused by TSH receptor antibodies in monozygotic twins: case reports," Endocrine Journal, vol. 45, no. 1, pp. 117-121, 1998.

[7] G. Aust, K. Krohn, N. G. Morgenthaler et al., "Graves' disease and Hashimoto's thyroiditis in monozygotic twins: case study as well as transcriptomic and immunohistological analysis of thyroid tissues," European Journal of Endocrinology, vol. 154, no. 1, pp. 13-20, 2006.

[8] W. A. Teft, M. G. Kirchhof, and J. Madrenas, "A molecular perspective of CTLA-4 function," Annual Review of Immunology, vol. 24, pp. 65-97, 2006.

[9] Y. Tomer, E. Concepcion, and D. A. Greenberg, "A C/T singlenucleotide polymorphism in the region of the CD40 gene is associated with Graves' disease," Thyroid, vol. 12, no. 12, pp. 1129-1135, 2002.

[10] Y. Ban, T. Tozaki, M. Taniyama, M. Tomita, and Y. Ban, "The codon 620 single nucleotide polymorphism of the protein tyrosine phosphatase- 22 gene does not contribute to autoimmune thyroid disease susceptibility in the Japanese," Thyroid, vol. 15, no. 10, pp. 1115-1118, 2005.
[11] Y. Ban, D. A. Greenberg, E. Concepcion, L. Skrabanek, R. Villanueva, and Y. Tomer, "Amino acid substitutions in the thyroglobulin gene are associated with susceptibility to human and murine autoimmune thyroid disease," Proceedings of the National Academy of Sciences of the United States of America, vol. 100, no. 25, pp. 15119-15124, 2003.

[12] X. Yin, R. Latif, R. Bahn, Y. Tomer, and T. F. Davies, "Influence of the TSH receptor gene on susceptibility to Graves' disease and Graves' ophthalmopathy," Thyroid, vol. 18, no. 11, pp. 1201-1206, 2008.

[13] Y. Ban, T. F. Davies, D. A. Greenberg et al., "Arginine at position 74 of the HLA-DR $\beta 1$ chain is associated with Graves' disease," Genes and Immunity, vol. 5, no. 3, pp. 203208, 2004.

[14] T. H. Brix, K. O. Kyvik, K. Christensen, and L. Hegedüs, "Evidence for a major role of heredity in Graves' disease: a population-based study of two Danish twin cohorts," Journal of Clinical Endocrinology and Metabolism, vol. 86, no. 2, pp. 930-934, 2001.

[15] N. R. Rose, R. Bonita, and C. L. Burek, "Iodine: an environmental trigger of thyroiditis," Autoimmunity Reviews, vol. 1, no. 1-2, pp. 97-103, 2002.

[16] H. S. Li, H. Y. Jiang, and G. Carayanniotis, "Modifying effects of iodine on the immunogenicity of thyroglobulin peptides," Journal of Autoimmunity, vol. 28, no. 4, pp. 171-176, 2007.

[17] F. Bogazzi, L. Bartalena, M. Gasperi, L. E. Braverman, and E. Martino, "The various effects of amiodarone on thyroid function," Thyroid, vol. 11, no. 5, pp. 511-519, 2001.

[18] Y. Oppenheim, Y. Ban, and Y. Tomer, "Interferon induced autoimmune thyroid disease (AITD): a model for human autoimmunity," Autoimmunity Reviews, vol. 3, no. 5, pp. 388-393, 2004.

[19] Y. Tomer and T. F. Davies, "Infection, thyroid disease, and autoimmunity," Endocrine Reviews, vol. 14, no. 1, pp. 107120, 1993.

[20] S. P. Cox, D. I. W. Phillips, and C. Osmond, "Does infection initiate Graves disease?: a population based 10 year study," Autoimmunity, vol. 4, no. 1-2, pp. 43-49, 1989.

[21] D. I. W. Phillips, D. J. P. Barker, and B. R. Smith, "The geographical distribution of thyrotoxicosis in England according to the presence or absence of TSH-receptor antibodies," Clinical Endocrinology, vol. 23, no. 3, pp. 283-287, 1985.

[22] T. H. Brix, P. S. Hansen, L. Hegedüs, and B. E. Wenzel, "Too early to dismiss Yersinia enterocolitica infection in the aetiology of Graves' disease: evidence from a twin casecontrol study," Clinical Endocrinology, vol. 69, no. 3, pp. 491496, 2008.

[23] S. Chatzipanagiotou, J. N. Legakis, F. Boufidou, V. Petroyianni, and C. Nicolaou, "Prevalence of Yersinia plasmid-encoded outer protein (Yop) class-specific antibodies in patients with Hashimoto's thyroiditis," Clinical Microbiology and Infection, vol. 7, no. 3, pp. 138-143, 2001.

[24] M. H. S. Kraemer, E. A. Donadi, M. A. Tambascia, L. A. Magna, and L. S. Prigenzi, "Relationship between HLA antigens and infectious agents in contributing towards the development of Graves' disease," Immunological Investigations, vol. 27, no. 1-2, pp. 17-29, 1998.

[25] A. Nagasaka, A. Nakai, N. Oda, M. Kotake, K. Iwase, and S. Yoshida, "Reverse transcriptase is elevated in the thyroid tissue from Graves' disease patients," Clinical Endocrinology, vol. 53, no. 2, pp. 155-159, 2000.

[26] K. Yokoi, H. Kawai, M. Akaike, H. Mine, and S. Saito, "Presence of human T-lymphotropic virus type II-related 
genes in DNA of peripheral leukocytes from patients with autoimmune thyroid diseases," Journal of Medical Virology, vol. 45, no. 4, pp. 392-398, 1995.

[27] N. Figura, G. Di Cairano, F. Lorè et al., "The infection by Helicobacter pylori strains expressing CagA is highly prevalent in women with autoimmune thyroid disorders," Journal of Physiology and Pharmacology, vol. 50, no. 5, pp. 817-826, 1999.

[28] Y. Tomer and R. Villanueva, "Hepatitis C and thyroid autoimmunity: is there a link?" American Journal of Medicine, vol. 117, no. 1, pp. 60-61, 2004.

[29] U. Watanabe, E. Hashimoto, T. Hisamitsu, H. Obata, and N. Hayashi, "The risk factor for development of thyroid disease during interferon- $\alpha$ therapy for chronic hepatitis C," American Journal of Gastroenterology, vol. 89, no. 3, pp. 399403, 1994.

[30] C. Carella, G. Mazziotti, F. Morisco et al., "The addition of ribavirin to interferon- $\alpha$ therapy in patients with hepatitis $\mathrm{C}$ virus-related chronic hepatitis does not modify the thyroid autoantibody pattern but increases the risk of developing hypothyroidism," European Journal of Endocrinology, vol. 146, no. 6, pp. 743-749, 2002.

[31] A. Antonelli, C. Ferri, P. Fallahi et al., "Thyroid disorders in chronic hepatitis C virus infection," Thyroid, vol. 16, no. 6, pp. 563-572, 2006.

[32] M. B. A. Oldstone, "Molecular mimicry and autoimmune disease," Cell, vol. 50, no. 6, pp. 819-820, 1987.

[33] G. J. Fournié, M. Mas, B. Cautain et al., "Induction of autoimmunity through bystander effects. Lessons from immunological disorders induced by heavy metals," Journal of Autoimmunity, vol. 16, no. 3, pp. 319-326, 2001.

[34] S. Lafranchi, "Thyroiditis and acquired hypothyroidism," Pediatric Annals, vol. 21, no. 1, pp. 29-39, 1992.

[35] G. Z. Ostergaard and B. B. Jacobsen, "Atrophic, autoimmune thyroiditis in infancy. A case report," Hormone Research, vol. 31, no. 4, pp. 190-192, 1989.

[36] C. M. Dayan and G. H. Daniels, "Chronic autoimmune thyroiditis," The New England Journal of Medicine, vol. 335, no. 2, pp. 99-107, 1996.

[37] E. L. Germain and L. P. Plotnick, "Age-related anti-thyroid antibodies and thyroid abnormalities in turner syndrome," Acta Paediatrica Scandinavica, vol. 75, no. 5, pp. 750-755, 1986.

[38] G. Oderda, A. Rapa, A. Zavallone, L. Strigini, and G. Bona, "Thyroid autoimmunity in childhood celiac disease," Journal of Pediatric Gastroenterology and Nutrition, vol. 35, no. 5, pp. 704-705, 2002.

[39] O. Kordonouri, A. Klinghammer, E. B. Lang, A. GrütersKieslich, M. Grabert, and R. W. Holl, "Thyroid autoimmunity in children and adolescents with type 1 diabetes: a multicenter survey," Diabetes Care, vol. 25, no. 8, pp. 1346 1350, 2002.

[40] P. Cambiaso, C. Orazi, M. C. Digilio et al., "Thyroid morphology and subclinical hypothyroidism in children and adolescents with Williams syndrome," Journal of Pediatrics, vol. 150, no. 1, pp. 62-65, 2007.

[41] A. Chiesa, L. Gruñeiro de Papendieck, A. Keselman, J. J. Heinrich, and C. Bergadá, "Final height in long-term primary hypothyroid children," Journal of Pediatric Endocrinology and Metabolism, vol. 11, no. 1, pp. 51-58, 1998.

[42] B. Boersma, B. J. Otten, G. B. A. Stoelinga, and J. M. Wit, "Catch-up growth after prolonged hypothyroidism," European Journal of Pediatrics, vol. 155, no. 5, pp. 362-367, 1996.
[43] M. Castro-Magaña, M. Angulo, A. Cañas, A. Sharp, and B. Fuentes, "Hypothalamic-pituitary gonadal axis in boys with primary hypothyroidism and macroorchidism," Journal of Pediatrics, vol. 112, no. 3, pp. 397-402, 1988.

[44] E. A. Jannini, S. Ulisse, and M. D'Armiento, "Macroorchidism in juvenile hypothyroidism," Journal of Clinical Endocrinology and Metabolism, vol. 80, no. 8, pp. 2543-2544, 1995.

[45] J. N. Anasti, M. R. Flack, J. Froehlich, L. M. Nelson, and B. C. Nisula, "A potential novel mechanism for precocious puberty in juvenile hypothyroidism," Journal of Clinical Endocrinology and Metabolism, vol. 80, no. 1, pp. 276-279, 1995.

[46] A. C. Bianco, D. Salvatore, B. Gereben, M. J. Berry, and P. R. Larsen, "Biochemistry, cellular and molecular biology, and physiological roles of the iodothyronine selenodeiodinases," Endocrine Reviews, vol. 23, no. 1, pp. 38-89, 2002.

[47] T. P. Foley Jr., "Mediators of thyroid diseases in children," Journal of Pediatrics, vol. 132, no. 4, pp. 569-570, 1998.

[48] V. Enăchescu, M. Popescu, and M. Bistriceanu, "Conventional and Doppler ultrasound in thyroid disease diagnosis," Revista medico-chirurgicalã a Societãţii de Medici şi Naturalişti din Iaşi, vol. 110, no. 3, pp. 511-520, 2006.

[49] S. L. Hancock, I. R. McDougall, and L. S. Constine, "Thyroid abnormalities after therapeutic external radiation," International Journal of Radiation Oncology Biology Physics, vol. 31, no. 5, pp. 1165-1170, 1995.

[50] K. Bessho, Y. Etani, H. Ichimori et al., "Increased type 3 iodothyronine deiodinase activity in a regrown hepatic hemangioma with consumptive hypothyroidism," European Journal of Pediatrics, vol. 119, pp. 492-502, 2010.

[51] S. J. Mandel, G. A. Brent, and P. R. Larsen, "Levothyroxine therapy in patients with thyroid disease," Annals of Internal Medicine, vol. 119, no. 6, pp. 492-502, 1993.

[52] C. Van Dop, F. A. Conte, T. K. Koch, S. J. Clark, S. L. Wilson-Davis, and M. M. Grumbach, "Pseudotumor cerebri associated with initiation of levothyroxine therapy for juvenile hypothyroidism," The New England Journal of Medicine, vol. 308, no. 18, pp. 1076-1080, 1983.

[53] A. H. Slyper and P. Swenerton, "Experience with lowdose replacement therapy in the initial management of severe pediatric acquired primary hypothyroidism," Journal of Pediatric Endocrinology and Metabolism, vol. 11, no. 4, pp. 543-547, 1998.

[54] T. Kuroiwa, Y. Okabe, K. Hasuo, K. Yasumori, A. Mizushima, and K. Masuda, "MR imaging of pituitary hypertrophy due to juvenile primary hypothyroidism: a case report," Clinical Imaging, vol. 15, no. 3, pp. 202-205, 1991.

[55] M. Ahmed, M. Banna, N. Sakati, and N. Woodhouse, "Pituitary gland enlargement in primary hypothyroidism: a report of 5 cases with follow-up data," Hormone Research, vol. 32, no. 5-6, pp. 188-192, 1989.

[56] S. Gopalakrishnan and R. K. Marwaha, "Juvenile autoimmune thyroiditis," Journal of Pediatric Endocrinology and Metabolism, vol. 20, no. 9, pp. 961-970, 2007.

[57] S. Gopalakrishnan, P. K. Chugh, M. Chhillar, V. K. Ambardar, M. Sahoo, and R. Sankar, "Goitrous autoimmune thyroiditis in a pediatric population: a longitudinal study," Pediatrics, vol. 122, no. 3, pp. e670-e674, 2008.

[58] G. Radetti, E. Gottardi, G. Bona, A. Corrias, S. Salardi, and S. Loche, "The natural history of euthyroid Hashimoto's thyroiditis in children," Journal of Pediatrics, vol. 149, no. 6, pp. 827-832, 2006.

[59] S. Jaruratanasirikul, K. Leethanaporn, P. Khuntigij, and H. Sriplung, “The clinical course of Hashimoto's thyroiditis in 
children and adolescents: 6 years longitudinal follow-up," Journal of Pediatric Endocrinology and Metabolism, vol. 14, no. 2, pp. 177-184, 2001.

[60] D. C. Moore, "Natural course of 'subclinical' hypothyroidism in childhood and adolescence," Archives of Pediatrics and Adolescent Medicine, vol. 150, no. 3, pp. 293-297, 1996.

[61] M. Wasniewska, M. Salerno, A. Cassio et al., "Prospective evaluation of the natural course of idiopathic subclinical hypothyroidism in childhood and adolescence," European Journal of Endocrinology, vol. 160, no. 3, pp. 417-421, 2009.

[62] J. J. Díez and P. Iglesias, "Spontaneous subclinical hypothyroidism in patients older than 55 years: an analysis of natural course and risk factors for the development of overt thyroid failure," Journal of Clinical Endocrinology and Metabolism, vol. 89, no. 10, pp. 4890-4897, 2004.

[63] H. Yoshida, N. Amino, K. Yagawa et al., "Association of serum antithyroid antibodies with lymphocytic infiltration of the thyroid gland: studies of seventy autopsied cases," Journal of Clinical Endocrinology and Metabolism, vol. 46, no. 6, pp. 859-862, 1978.

[64] A. Corrias, A. Cassio, G. Weber et al., "Thyroid nodules and cancer in children and adolescents affected by autoimmune thyroiditis," Archives of Pediatrics and Adolescent Medicine, vol. 162, no. 6, pp. 526-531, 2008.

[65] A. Corrias, A. Mussa, F. Baronio et al., "Diagnostic features of thyroid nodules in pediatrics," Archives of Pediatrics and Adolescent Medicine, vol. 164, no. 8, pp. 714-719, 2010.

[66] M. E. Dailey, S. Lindsay, and R. Skahen, "Relation of thyroid neoplasms to Hashimoto disease of the thyroid gland," AMA Archives of Surgery, vol. 70, pp. 291-297, 1955.

[67] H. J. Carson, M. J. Castelli, and P. Gattuso, "Incidence of neoplasia in Hashimoto's thyroiditis: a fine-needle aspiration study," Diagnostic Cytopathology, vol. 14, no. 1, pp. 38-42, 1996.

[68] R. A. Ott, D. B. Calandra, and A. McCall, "The incidence of thyroid carcinoma in patients with Hashimoto's thyroiditis and solitary cold nodules," Surgery, vol. 98, no. 6, pp. 1202 1206, 1985.

[69] M. Niedziela, "Pathogenesis, diagnosis and management of thyroid nodules in children," Endocrine-Related Cancer, vol. 13, no. 2, pp. 427-453, 2006.

[70] B. S. Chertow, W. J. Fidler, and B. L. Fariss, "Graves' disease and Hashimoto's thyroiditis in monozygous twins," Acta Endocrinologica, vol. 72, no. 1, pp. 18-24, 1973.

[71] T. H. Brix, K. O. Kyvik, and L. Hegedüs, "A population-based study of chronic autoimmune hypothyroidism in Danish twins," Journal of Clinical Endocrinology and Metabolism, vol. 85, no. 2, pp. 536-539, 2000.

[72] M. P. Desai and S. Karandikar, "Autoimmune thyroid disease in childhood: a study of children and their families," Indian Pediatrics, vol. 36, no. 7, pp. 659-668, 1999.

[73] D. Doniach, "Humoral and genetic aspects of thyroid autoimmunity," Clinics in Endocrinology and Metabolism, vol. 4, no. 2, pp. 267-285, 1975.

[74] L. C. Wood and S. H. Ingbar, "Hypothyroidism as a late sequela in patient with Graves' disease treated with antithyroid agents," Journal of Clinical Investigation, vol. 64, no. 5, pp. 1429-1436, 1979.

[75] N. Takasu, T. Yamada, A. Sato et al., “Graves' disease following hypothyroidism due to Hashimoto's disease: studies of eight cases," Clinical Endocrinology, vol. 33, no. 6, pp. 687698, 1990.

[76] J. P. le Berre, C. Rousseau, O. Dupuy, L. Bordier, H. Mayaudon, and B. Bauduceau, "Unusual evolution of autoimmune hypothyroidism: occurrence of Graves' disease," Revue de Medecine Interne, vol. 25, pp. 841-843, 2004 (French).

[77] Y. Tomer, Y. Ban, E. Conception et al., "Common and unique susceptibility loci in graves and hashimoto diseases: results of whole-genome screening in a data set of 102 multiplex families," American Journal of Human Genetics, vol. 73, no. 4, pp. 736-747, 2003.

[78] M. Wasniewska, A. Corrias, T. Arrigo et al., "Frequency of Hashimoto's thyroiditis antecedents in the history of children and adolescents with Graves' disease," Hormone Research in Paediatrics, vol. 73, no. 6, pp. 473-476, 2010.

[79] D. Zimmerman and A. N. Lteif, "Thyrotoxicosis in children," Endocrinology and Metabolism Clinics of North America, vol. 27, no. 1, pp. 109-126, 1998.

[80] A. Grüters, "Ocular manifestations in children and adolescents with thyrotoxicosis," Experimental and Clinical Endocrinology and Diabetes, vol. 107, no. 5, pp. S172-S174, 1999.

[81] J. M. H. Buckler, H. Willgerodt, and E. Keller, "Growth in thyrotoxicosis," Archives of Disease in Childhood, vol. 61, no. 5, pp. 464-471, 1986.

[82] G. W. K. Wong, J. Lai, and P. S. Cheng, "Growth in childhood thyrotoxicosis," European Journal of Pediatrics, vol. 158, no. 10, pp. 776-779, 1999.

[83] E. Marqusee, S. T. Haden, and R. D. Utiger, "Subclinical thyrotoxicosis," Endocrinology and Metabolism Clinics of North America, vol. 27, no. 1, pp. 37-49, 1998.

[84] D. A. Koutras, "Subclinical hyperthyroidism," Thyroid, vol. 9, no. 3, pp. 311-315, 1999.

[85] J. A. Franklyn, "The management of hyperthyroidism," The New England Journal of Medicine, vol. 330, no. 24, pp. 17311738, 1994.

[86] S. A. Rivkees and A. Szarfman, "Dissimilar hepatotoxicity profiles of propylthiouracil and methimazole in children," Journal of Clinical Endocrinology and Metabolism, vol. 95, no. 7, pp. 3260-3267, 2010.

[87] S. A. Rivkees, "63 years and 715 days to the "boxed warning": unmasking of the propylthiouracil problem," International Journal of Pediatric Endocrinology, vol. 2010, Article ID 658267, 3 pages, 2010.

[88] I. Klein, D. V. Becker, and G. S. Levey, "Treatment of hyperthyroid disease," Annals of Internal Medicine, vol. 121, no. 4, pp. 281-288, 1994.

[89] A. Lucas, I. Salinas, F. Rius et al., "Medical therapy of Graves' disease: does thyroxine prevent recurrence of hyperthyroidism?" Journal of Clinical Endocrinology and Metabolism, vol. 82, no. 8, pp. 2410-2413, 1997.

[90] S. A. Rivkees, C. Sklar, and M. Freemark, "The management of Graves' disease in children, with special emphasis on radioiodine treatment," Journal of Clinical Endocrinology and Metabolism, vol. 83, no. 11, pp. 3767-3775, 1998.

[91] S. H. Lafranchi and C. E. Hanna, "Graves disease in the neonatal period and childhood," in Werner \& Ingbar's the Thyroid. A Fundamental and Clinical Text, L. E. Braverman and R. D. Utiger, Eds., pp. 989-997, Lipppincott Williams \& Wilkins, Philadelphia, Pa, USA, 2000.

[92] J. Raza, P. C. Hindmarsh, and C. G. D. Brook, "Thyrotoxicosis in children: thirty years' experience," Acta Paediatrica, vol. 88, no. 9, pp. 937-941, 1999.

[93] G. W. Moll Jr. and B. R. Patel, "Pediatric graves' disease: therapeutic options and experience with radioiodine at the University of Mississippi Medical Center," Southern Medical Journal, vol. 90, no. 10, pp. 1017-1022, 1997. 
[94] L. Ward, C. Huot, R. Lambert, C. Deal, R. Collu, and G. Van Vliet, "Outcome of pediatric Graves' disease after treatment with antithyroid medication and radioiodine," Clinical and Investigative Medicine, vol. 22, no. 4, pp. 132-139, 1999.

[95] J. D. Clark, M. J. Gelfand, and A. H. Elgazzar, "Iodine-131 therapy of hyperthyroidism in pediatric patients," Journal of Nuclear Medicine, vol. 36, no. 3, pp. 442-445, 1995.

[96] E. K. Alexander and P. R. Larsen, "High dose ${ }^{131}$ I therapy for the treatment of hyperthyroidism caused by Graves' disease," Journal of Clinical Endocrinology and Metabolism, vol. 87, no. 3, pp. 1073-1077, 2002.

[97] T. D. Cheetham, P. Wraight, I. A. Hughes, and N. D. Barnes, "Radioiodine treatment of Graves' disease in young people," Hormone Research, vol. 49, no. 6, pp. 258-262, 1998.

[98] K. Baverstock, B. Egloff, A. Pinchera, C. Ruchti, and D. Williams, "Thyroid cancer after Chernobyl," Nature, vol. 359, no. 6390, pp. 21-22, 1992.

[99] Y. Nikiforov, D. R. Gnepp, and J. A. Fagin, “Thyroid lesions in children and adolescents after the Chernobyl disaster: implications for the study of radiation tumorigenesis," Journal of Clinical Endocrinology and Metabolism, vol. 81, no. 1, pp. 9-14, 1996.

[100] L. Bartalena, C. Marcocci, F. Bogazzi et al., "Relation between therapy for hyperthyroidism and the course of Graves' ophthalmopathy," The New England Journal of Medicine, vol. 338, no. 2, pp. 73-78, 1998.

[101] J.-A. Söreide, J. A. van Heerden, C.-Y. Lo, C. S. Grant, D. Zimmerman, and D. M. Ilstrup, "Surgical treatment of Graves' disease in patients younger than 18 years," World Journal of Surgery, vol. 20, no. 7, pp. 794-799, 1996, discussion 799-800.

[102] J. A. Sosa, H. M. Bowman, J. M. Tielsch, N. R. Powe, T. A. Gordon, and R. Udelsman, "The importance of surgeon experience for clinical and economic outcomes from thyroidectomy," Annals of Surgery, vol. 228, no. 3, pp. 320$330,1998$.

[103] J. H. T. Waldhausen, "Controversies related to the medical and surgical management of hyperthyroidism in children," Seminars in Pediatric Surgery, vol. 6, no. 3, pp. 121-127, 1997.

[104] N. Momotani, K. Ito, and N. Hamada, "Maternal hyperthyroidism and congenital malformation in the offspring," Clinical Endocrinology, vol. 20, no. 6, pp. 695-700, 1984.

[105] S. J. Mandel and D. S. Cooper, "Commentary: the use of antithyroid drugs in pregnancy and lactation," Journal of Clinical Endocrinology and Metabolism, vol. 86, no. 6, pp. 2354-2359, 2001.

[106] J. T. Dunn and F. Delange, "Damaged reproduction: the most important consequence of iodine deficiency," Journal of Clinical Endocrinology and Metabolism, vol. 86, no. 6, pp. 2360-2363, 2001.

[107] D. Zimmerman, "Fetal and neonatal hyperthyroidism," Thyroid, vol. 9, no. 7, pp. 727-733, 1999.

[108] P. Laurberg, C. Bournaud, J. Karmisholt, and J. Orgiazzi, "Management of Graves' hyperthyroidism in pregnancy: focus on both maternal and foetal thyroid function, and caution against surgical thyroidectomy in pregnancy," European Journal of Endocrinology, vol. 160, no. 1, pp. 1-8, 2009.

[109] M. Polak, I. Legac, E. Vuillard, J. Guibourdenche, M. Castanet, and D. Luton, "Congenital hyperthyroidism: the fetus as a patient," Hormone Research, vol. 65, no. 5, pp. 235242, 2006.

[110] N. K. Agrawal, R. Goyal, A. Rastogi, D. Naik, and S. K. Singh, "Thyroid hormone resistance," Postgraduate Medical Journal, vol. 84, no. 995, pp. 473-477, 2008. 


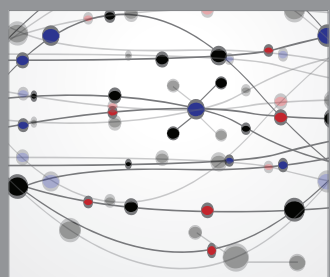

The Scientific World Journal
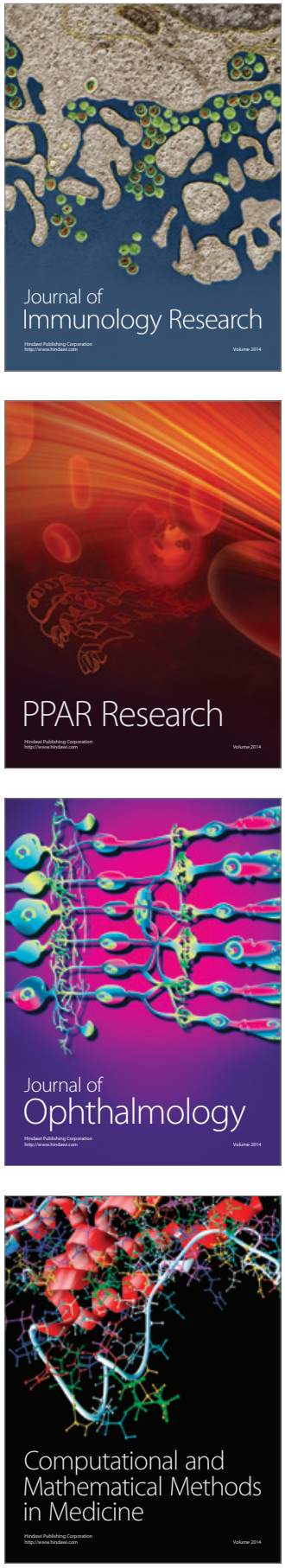

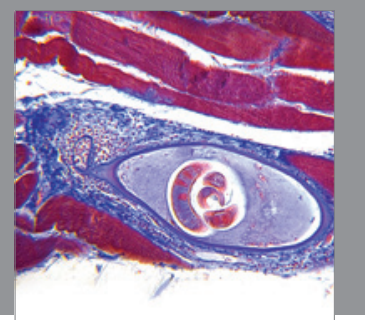

Gastroenterology

Research and Practice
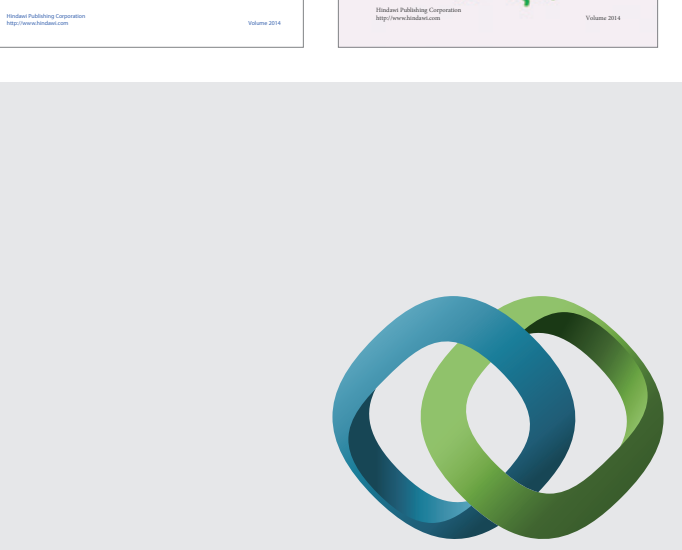

\section{Hindawi}

Submit your manuscripts at

http://www.hindawi.com
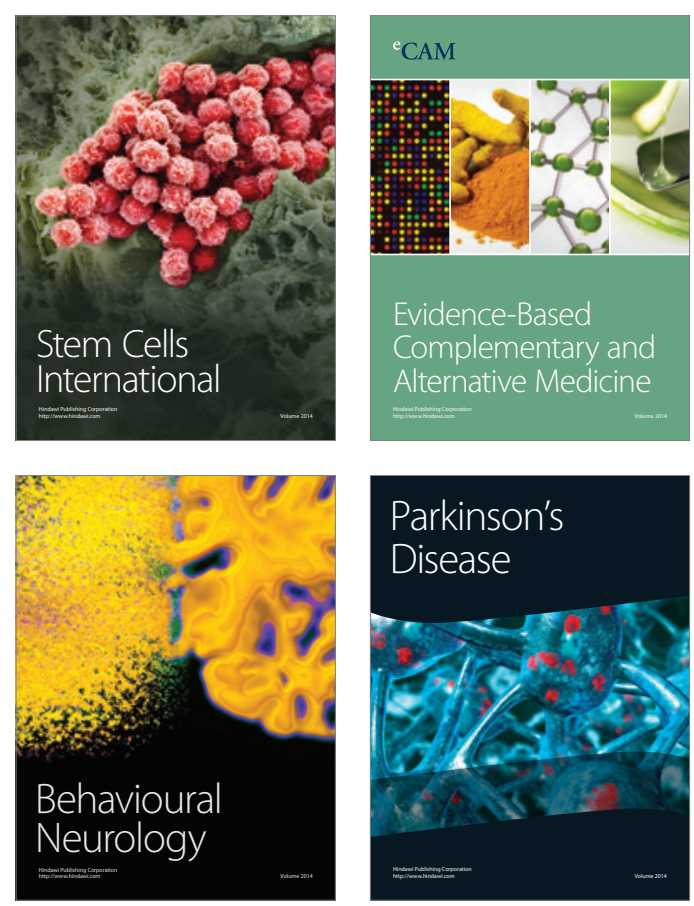

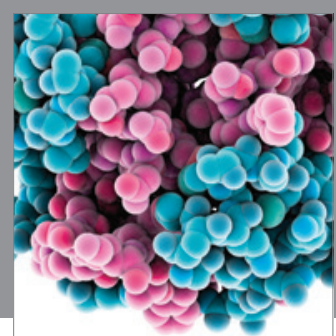

Journal of
Diabetes Research

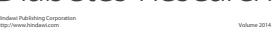

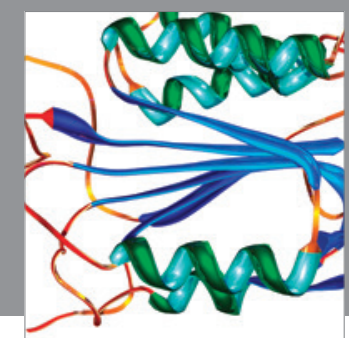

Disease Markers
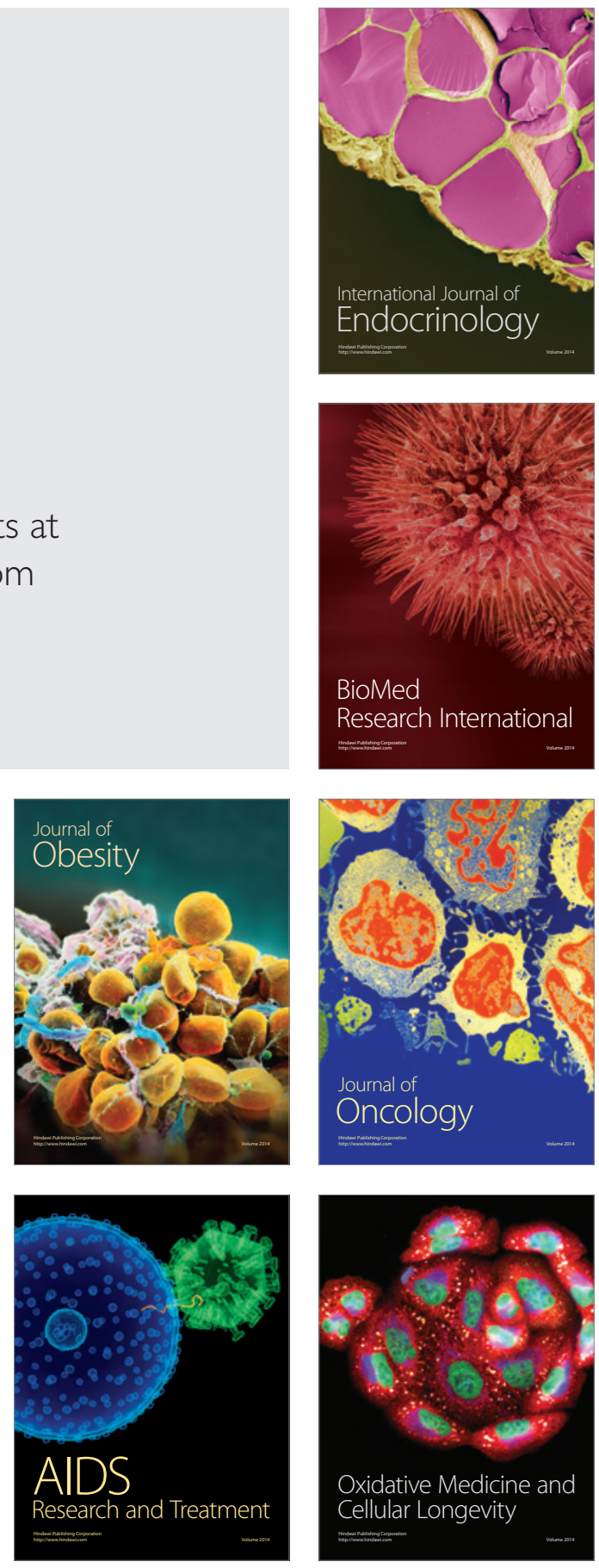